\title{
Effects of different concentrations of human umbilical cord mesenchymal stem cells to ameliorate psoriasis-like skin lesions in BALB/c mice
}

\author{
Youshu Lin ${ }^{1 \#}$, Hongwei Wang ${ }^{2 \#}$, Cuibao Jiang ${ }^{2}$, Chen Chen ${ }^{2}$, Danpeng Shen ${ }^{2}$, Fan Xie ${ }^{2}$, \\ Hongpeng Zhang ${ }^{2}$, Jie Yang ${ }^{1 \wedge}$, Hao Wang ${ }^{2}$
}

${ }^{1}$ Department of Cosmetic Dermatology, The Fifth People's Hospital of Hainan Province, Haikou, China; ${ }^{2}$ Asia Stem Cell Regenerative Pharmaceutical Co., Ltd., Shanghai, China

Contributions: (I) Conception and design: J Yang; (II) Administrative support: Hao Wang; (III) Provision of study materials or patients: Hongwei Wang, C Jiang, H Zhang; (IV) Collection and assembly of data: Y Lin; (V) Data analysis and interpretation: C Chen, D Shen, F Xie; (VI) Manuscript writing: All authors; (VII) Final approval of manuscript: All authors.

"These authors contributed equally to this work and should be considered as co-first authors.

Correspondence to: Jie Yang. Department of Cosmetic Dermatology, The Fifth People's Hospital of Hainan Province, Haikou, China.

Email: 13337564169@163.com; Hao Wang. Asia Stem Cell Regenerative Pharmaceutical Co., Ltd., Shanghai, China.

Email: wanghao@xibaozhiliao.cn.

Background: Psoriasis is an immune-mediated chronic, recurrent, inflammatory skin disease. In view of the research on the relationship between stem cells and the pathogenesis of psoriasis, stem cells may be a new breakthrough in the systemic treatment of psoriasis.

Methods: The BALB/c mouse psoriasis-like model induced by imiquimod was established and animals were randomly divided into a control group, model group, human umbilical cord mesenchymal stem cells (hUCMSCs) group with different concentrations (injected separately with umbilical cord stem cells $1 \times 10^{7} / \mathrm{kg}$, $2 \times 10^{7} / \mathrm{kg}, 4 \times 10^{7} / \mathrm{kg}$ through the caudal vein) and fresh hUC-MSCs group (injected with fresh umbilical cord stem cells $2 \times 10^{7} / \mathrm{kg}$ through the tail vein). The Psoriasis Area and Severity Index (PASI) score was used to observe the changes in skin lesions. The epidermal thickness, degree of keratinization and infiltration of inflammatory cells were observed by $\mathrm{HE}$ staining. The concentrations of $T N F-\alpha, I F N-\gamma, I L-17 A, I L-23$ and other cytokines in serum and skin of mice were measured by enzyme-linked immunosorbent assay (ELISA).

Results: Mice treated with hUC-MSCs showed a good dose-response dependence compared with the control group. As the concentration of hUC-MSCs increased, so did the spleen index. According to the PASI integral trend chart, hUC-MSCs can delay the appearance of skin lesions and accelerate the recovery of skin lesions. HE staining showed that the number of parakeratosis cells in the hUC-MSCs treatment group was significantly decreased, and the degree of dermal hyperplasia and inflammatory cell infiltration in erythrocyte extravasation was significantly lower than in the model group. The higher the concentration of hUC-MSCs, the lower the concentration of the four cytokines in serum and skin tissue.

Conclusions: hUC-MSCs had an obvious therapeutic effect on imiquimod-induced psoriasis in mice, and a high concentration of hUC-MSCs had the best therapeutic effect. This effect intensity is dose-dependent, and hUC-MSCs at high concentrations have better therapeutic effect.

Keywords: Cytokines; indirubin; human umbilical cord mesenchymal stem cells (hUC-MSCs); psoriasis

Submitted Nov 12, 2021. Accepted for publication Jan 19, 2022.

doi: $10.21037 / \mathrm{atm}-22-4$

View this article at: https://dx.doi.org/10.21037/atm-22-4

^ ORCID: 0000-0002-2583-0225. 


\section{Introduction}

Psoriasis is an immune-mediated chronic, recurrent, inflammatory skin disease with typical clinical manifestations of scaly erythema or plaques that can be localized or widely distributed (1). The etiology of psoriasis involves genetic, immune, environmental and other factors $(2,3)$. Psoriasis leads to excessive keratinocyte proliferation or inflammation of synovial cells and chondrocytes through an immune response mainly mediated by $\mathrm{T}$ lymphocytes and jointly participated in by multiple immune cells $(4,5)$.

The treatment plan for psoriasis is determined according to the patient's symptoms, with external treatment as the mainstay for mild psoriasis, systematic treatment for moderate and severe psoriasis, and targeted biologics as the appropriate treatment for patients with poor response to traditional systemic drug therapy $(5,6)$. The clinical PASI scoring system was used to determine the degree of psoriasis. Since the area of skin lesions was artificially interfered, the score was mainly based on the severity of skin lesions. The erythema, scaling, and infiltration were scored separately as 0 (not present); 1 (slight); 2 (moderate); 3 (severe); and 4 (extremely severe), from which, the scores were summed up for a total score.

Systemic therapeutic drugs currently used mainly include methotrexate, cyclosporine, retinoids, azathioprine, mortimecofenate and other immunosuppressants (7-11), but the use of immunosuppressants is often limited by adverse drug reactions, so long-term drug administration is not possible (12). In recent years, a series of biologic agents and small molecule drugs with specific targets for psoriasis have been developed one after another, and they have achieved good clinical efficacy, but the long-term efficacy and safety remain to be observed, and common characteristics such as efficacy attenuation may lead to treatment failure. Therefore, the treatment of psoriasis still needs more options.

Psoriasis is associated with abnormal keratinocytes, immune cells, hematopoietic stem cells (HSCs), vascular endothelial cells, and bone marrow mesenchymal stem cells (MSCs) $(13,14)$. HSCs from patients with psoriasis produce subsets of $\mathrm{T}$ cells with a tendency to secrete $T h 1$ cytokines and subsets of dysfunctional Treg cells. Once activated by internal or external environmental factors, psoriatic $\mathrm{T}$ cells are prone to a $T h 1$ immune response, which not only induces epidermal stem cells to produce more transient amplifying cells, eventually leading to overproliferation of keratinocytes, but can also promote the transformation of MSCs into a pro-inflammatory cell MSC1 phenotype, contribute to angiogenesis and infiltration of psoriatic skin lymphocytes by inflammatory cytokines and chemokines, and aggravate the local $T b 1$ immune response (15-17). MSCs have broad clinical application prospects, and can be used to treat diseases of nervous system, liver and kidney injury, autoimmune diseases, ischemic vascular diseases, diabetes complications and tumors. In addition, mesenchymal stem cells have been found in umbilical cord blood, periodontal ligaments, dermis, skeletal muscle, placenta and pancreas.

In view of the research on the relationship between stem cells and the pathogenesis of psoriasis, stem cells may be a new breakthrough in the systemic treatment of psoriasis. However, it is necessary to investigate the effective concentration of stem cells in the treatment of psoriasis while observing their therapeutic effect. We investigated the efficacy and effective concentration of human MSCs in delaying psoriatic lesions in mice in vitro. Because changes in the levels of cytokine can indirectly reflect the changing trend of skin lesions, four cytokines, interferon (IFN)- $\gamma$, tumor-necrosis factor (TNF)- $\alpha$, interleukin $(I L)-17$ and $I L-12$, were selected to reflect the effect of the stem cell treatment. We found that hUC-MSCs (human umbilical cord mesenchymal stem cells) have a therapeutic effect on imiquimod-induced psoriasis in mice by inhibiting the concentration of $I L-23$ and $I L-17$ factors, and may become a new therapeutic approach for clinical treatment of psoriasis.

We present the following article in accordance with the ARRIVE reporting checklist (available at https://atm. amegroups.com/article/view/10.21037/atm-22-4/rc).

\section{Methods}

\section{Main reagents and materials}

Imiquimod 5\% cream (batch no. 17010139), purchased from Sichuan Mingxin Lidi Company; Recombinant Mouse Interleukin 12 (rmIL-12 p70), BD Pharmingen Inc., batch no. 6278771, Specifications: $5 \mu \mathrm{g}$; lipopolysaccharide (LPS) lyophilized powder (Sigma, Inc., batch no. 045M4087V, specification: $10 \mathrm{mg}$ ); enzyme-linked immunosorbent assay (ELISA) kits for IL-17A, IL-12 (Shanghai Future Industry Co., Ltd., batch no. JL20171, JL20166). Compound electrolyte solution (Shanghai Kelun Pharmaceutical Co., Ltd., batch no. T14102120). Human umbilical cord MSCs (hUC-MSCs) were produced and prepared by the GMP laboratory of Shanghai Quansheng Biotechnology Co., Ltd. 
The UC donor gave signed informed consent to donate for scientific research and passed the infectious disease test. The collected UC tissues were cut and separated by slippage. After generation and amplification, they were prepared into $1 \times 10^{8}$ cells $/ \mathrm{mL}$ normal saline cell suspension (batch no. 20191201). After passing the quality inspection of sterility, mycoplasma, endotoxin and flow phenotype, they were used in this experiment. The experimental instruments were provided by Shanghai Quan Sheng Biotechnology Co., Ltd.

\section{Experimental animals}

\section{Statement of ethics}

Experiments were performed under a project license (No. 2016LL003) granted by institutional board of The Fifth People's Hospital of Hainan Province, in compliance with The Fifth People's Hospital of Hainan Province guidelines for the care and use of animals.

We purchased 60 SPF grade 6-8 weeks-old male BALB/c mice weighing about $20 \mathrm{~g}$ from Beijing Vitong Lihua Experimental Animal Co., Ltd. The animals were kept in the laboratory for at least 1 week and then tested under standard rearing conditions (room temperature $25-27^{\circ} \mathrm{C}$ ) with alternating light and dark cycles of $12 \mathrm{~h}$. The mice were allowed free access to food (standard pellet feed) and water.

\section{Experiment design}

Psoriasis-like lesions were induced in the BALB/c mice by applying $5 \%$ imiquimod cream at $62.5 \mathrm{mg} /$ day on the back of the mice for consecutive 7 days, as well as subcutaneously injecting $10 \mathrm{ng}(5 \mu \mathrm{L})$ of recombinant mouse interleukin (rmIL-12) and $20 \mu \mathrm{g}(5 \mu \mathrm{L})$ of LPS once at the beginning of model creation. During drug intervention, imiquimod $5 \%$ cream was applied every other day to avoid spontaneous regression of the skin lesions.

The BALB/c mice were randomly divided into six groups of 10 mice. Group A: normal control group; Group B: model group; Group C1: injected with UC stem cells $\left(1 \times 10^{7} / \mathrm{kg}\right)$ through the caudal vein; $\mathrm{C} 2$ group: injected with UC stem cells $2 \times 10^{7} / \mathrm{kg}$ through the caudal vein; $\mathrm{C} 3$ group: injected with UC stem cells $4 \times 10^{7} / \mathrm{kg}$ through the caudal vein; Group D: injected with fresh UC stem cells $2 \times 10^{7} / \mathrm{kg}$ through the tail vein. All mice were humanely killed after observation on the 7th day, and blood and dorsal skin tissue were collected for later use. The spleen was excised and weighed, and the spleen index (spleen mass/body mass) was calculated. Photographs were taken and recorded.

\section{Cell stemness identification}

\section{Flow cytometry}

The second-generation cells were collected and digested with $0.25 \%$ TrypLE trypsin (Gibco), and the appropriate amount of cells was incubated with CD73, CD90, CD105, CD34, CD45 and HLA-DR antibodies $(1 \mu \mathrm{g} / 100 \mu \mathrm{L}$, CST) that were coupled with PE (phycoerythrin) luminescent group on ice for $30 \mathrm{~min}$. Cell surface antibody levels were detected by flow cytometry (cytoFLEX, Beckman-Coulter).

\section{Osteogenesis}

hUC-MSCs were seeded into each well of a 6-well plates at a density of $1 \times 10^{5}$ cells/well. Next, $10 \mathrm{mmol} / \mathrm{L}$ $\beta$-glycerophosphate, $1 \mu \mathrm{mol} / \mathrm{L}$ dexamethasone and $50 \mu \mathrm{mol} / \mathrm{L}$ vitamin $\mathrm{C}$ were added to conventional medium for osteogenesis induction. The cells were cultured in the osteogenic induction medium for 4 weeks, and mineral bone nodules were detected with alizarin red $\mathrm{S}$ dye.

\section{Adipogenesis induction}

hUC-MSCs cells were seeded into each well of a 6-well plates at a density of $1 \times 10^{5}$ cells/well. Next, $0.5 \mathrm{mmol} / \mathrm{L}$ 3-isobutyl-1-methylxanthine, $200 \mu \mathrm{mol} / \mathrm{L}$ indomethacin, $1 \mu \mathrm{mol} / \mathrm{L}$ dexamethasone and $10 \mu \mathrm{mol} / \mathrm{L}$ insulin were added to conventional medium for adipogenesis induction. After cells were cultured in the adipogenic induction medium for 1 week, lipid droplets were detected with oil red $\mathrm{O}$ dye.

\section{Chondroblast induction}

hUC-MSCs cells were seeded into each well of a 6-well plates at a density of $1 \times 10^{5}$ cells/well. Conventional medium was supplemented with $10 \mu \mathrm{g} / \mathrm{L}$ transforming growth factor- $\beta 1,0.1 \mu \mathrm{mol} / \mathrm{L}$ dexamethasone, $100 \mu \mathrm{mol} / \mathrm{L}$ ascorbic acid, $200 \mathrm{mmol} / \mathrm{L}$ glutamine and $1 \%$ Insulin-TransferrinSelenium (ITS)as the medium for chondrogenic induction.

\section{Immunohistochemical assay}

The dorsal skin tissue was fixed with $4 \%$ paraformaldehyde, embedded with paraffin and sectioned at $5 \mu \mathrm{m}$ thickness. The tissue sections were placed on slides and baked in a thermostat at $60^{\circ} \mathrm{C}$ for $1 \mathrm{~h}$ until the wax on the surface of the tissue melted. The slides were dewaxed in xylene for $15 \mathrm{~min}$, then soaked in $100 \%$ ethanol for $5 \mathrm{~min}$, then in $95 \%, 90 \%, 80 \%$ and $70 \%$ ethanol for 2 min respectively, and washed with phosphate-buffered saline (PBS) three times for 3 min each time. The tissue sections were placed 
Table 1 Psoriasis area and severity index (PASI)

\begin{tabular}{|c|c|}
\hline Items & Details \\
\hline \multirow[t]{5}{*}{ Erythema } & 0 point: none \\
\hline & 1 point: slight \\
\hline & 2 points: moderate \\
\hline & 3 points: severe \\
\hline & 4 points: very severe \\
\hline \multirow[t]{5}{*}{ Induration/thickness } & 0 point: none \\
\hline & 1 point: slight \\
\hline & 2 points: moderate \\
\hline & 3 points: severe \\
\hline & 4 points: very severe \\
\hline \multirow[t]{5}{*}{ Desquamation/scaling } & 0 point: none \\
\hline & 1 point: slight \\
\hline & 2 points: moderate \\
\hline & 3 points: severe \\
\hline & 4 points: very severe \\
\hline
\end{tabular}

in a citrate buffer and boiled in a pressure cooker for $3 \mathrm{~min}$ for antigenic repair. They were washed with distilled water and PBS twice successively, $3 \mathrm{~min}$ each time. The section was sealed with $5 \%$ bovine serum protein for $10 \mathrm{~min}$, then the specific primary antibody was added to the section before incubation overnight at $4{ }^{\circ} \mathrm{C}$. The section was washed three times with PBS for 5 min each time, before secondary antibody was added and incubation at $37 \%$ for $1 \mathrm{~h}$, and then washed with PBS three times for $5 \mathrm{~min}$ each time. DAB was added, color developed for 5 minutes, and then the slides were rinsed with distilled water, before being dyed with hematoxylin for $10 \mathrm{~s}$. The sections were dehydrated by gradient ethanol for 2 min each and made transparent by xylene for $5 \mathrm{~min}$. Finally, the sections were sealed with resin for observation and photographing under a microscope.

\section{Appearance score test}

Psoriasis Area and Severity Index (PASI) were used to evaluate the appearance of the psoriasis lesions (Table 1). Since the area of skin lesions was artificially interfered, the score was mainly based on the severity of skin lesions.

\section{Pathological evaluation}

The dorsal skin tissue of the mice was fixed with $4 \%$ paraformaldehyde, embedded with paraffin and sectioned at $5 \mu \mathrm{m}$ thickness. All tissue sections were stained with hematoxylin-eosin (HE). The skin thickness was measured after photographing.

\section{Immunological evaluation}

Serum and the dorsal skin of the mice were collected and stored at $-80{ }^{\circ} \mathrm{C}$. The tissues were homogenized at $4{ }^{\circ} \mathrm{C}$, and the supernatant was collected and stored at $-20^{\circ} \mathrm{C}$. The concentrations of $T h 1$ and $T h 17$-related immune molecules tumor-necrosis factor (TNF)- $\alpha$, interferon $(I F N)-\gamma, I L$ $17 A$ and $I L-23$ in the serum and dorsal skin tissues were measured by ELISA kits. Procedures followed the manufacturer's instructions.

\section{Data collection and statistical analysis}

We used statistical software SPSS13.0 to process the data, and the measurement data are expressed as the mean \pm standard deviation.

\section{Results}

\section{General presentation and skin lesion scores}

In the experimental group, from the first day of modeling, minor psoriatic lesions appeared on the backs of the mice. Correspondingly, the PASI score increased day by day, and the overall trend of increase was obvious in each group. In the first 4 days, there was no significant difference in the PASI scores among the groups. On day 5 , the symptoms of psoriasis in other groups were significantly ameliorated, the scores decreased, and the skin lesions began to improve. The scores of the psoriatic lesions and PASI in model group $\mathrm{B}$ and low-dose group C1 gradually became higher than those in the other groups, while the PASI scores in the medium-dose and high-dose groups $\mathrm{C} 1$ and $\mathrm{C} 2$ began to stabilize and remained at a lower level. On the 7th day of medication, there was a good dose-dependent relationship among the high-dose, medium-dose and low-dose groups. Compared with the model group and $\mathrm{C} 1$ group, psoriatic symptoms in the other groups were significantly reduced (Figure 1). Group A was the normal control group and did not participate in the scoring. 



Figure 1 PASI scores of animals in each group: (A) erythema score, (B) scaliness score, (C) skin hypertrophy score, (D) total PASI scores of animals in each group. PASI, Psoriasis Area and Severity Index.

\section{Changes in dorsal skin lesions}

Changes in the dorsal skin lesions were observed by the naked eye (Figure 2). At 1 day after modeling, erythema appeared in each group and after 3-4 days, there was obvious scale formation. On the 5 th day, the scaly erythema began to increase, and spotty bleeding was observed after the scales fell off. On day 6, the erythema of model groups $\mathrm{B}$ and $\mathrm{C} 1$ was aggravated, the skin was obviously thickened, surface scaliness continued to increase, and the skin rash was similar in the appearance to human psoriatic lesions. However, from day 5, erythema, scaliness and infiltration in all treatment groups except living group D were significantly less than in model groups B and treatment C1.

\section{Spleen index results}

At the end of the experiment, the spleens of the animals in each group was measured and the spleen index (spleen index = spleen mass/body mass) was calculated (Figure 3). Both the spleen size and spleen index of mice in each group were significantly higher than those in control group A.
There was no significant difference in spleen index between the model groups $\mathrm{B}$ and the $\mathrm{C} 1$. The spleen index of the $\mathrm{C} 1, \mathrm{C} 2$ and $\mathrm{C} 3$ groups increased with increasing stem cell concentration.

\section{Pathologic results}

\section{Symptoms observed}

Observing the dorsal skin of the mice in each group, it could be seen that the epidermal layer of the mice in control group A was thinner, and only 1-2 layers of cells with normal morphology could be seen. Other groups showed obvious epidermal thickening that was greater than that of normal skin. There were Munro microabscesses in some locations, increased numbers of cells in the spinous layer, and a large number of inflammatory cells infiltrated the dermis, similar to the pathological changes of human psoriatic lesions. Skin lesions combined with pathological features proved that the imiquimod cream + LPS/IL12 induced psoriasis model was successful. Compared with model group B, the number of parakeratosis cells in 
A

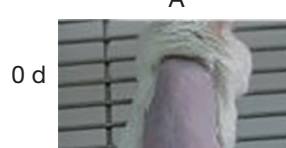

$1 \mathrm{~d}$
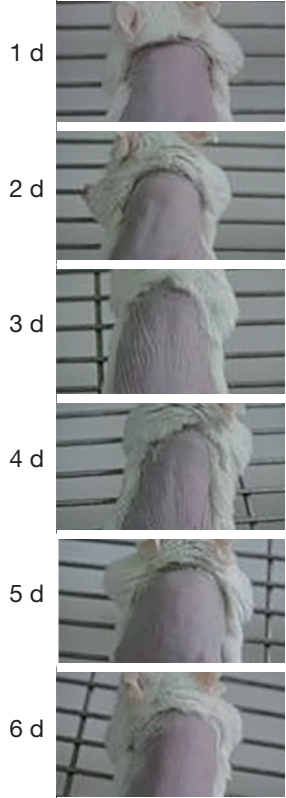

$7 \mathrm{~d}$

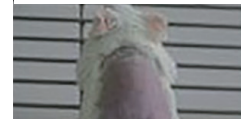

B
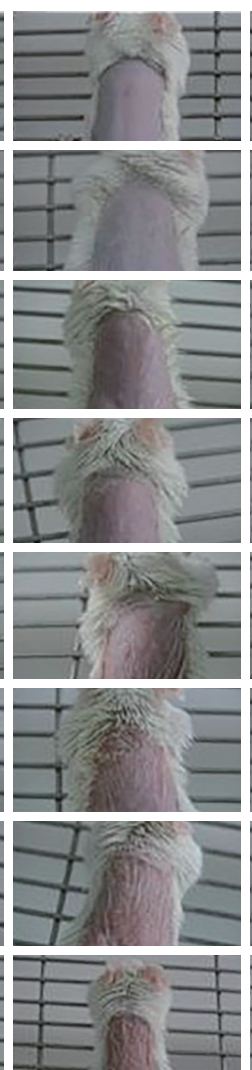

C1
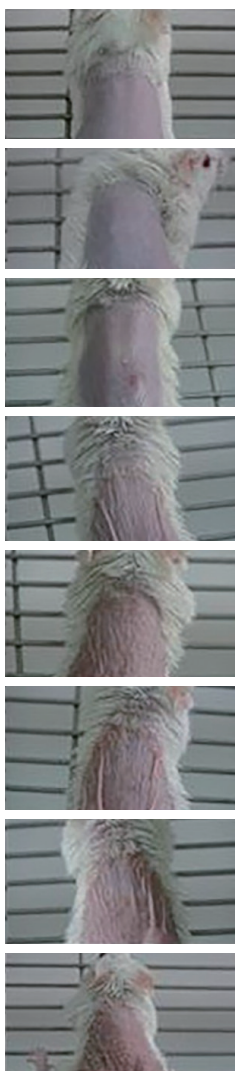

C2
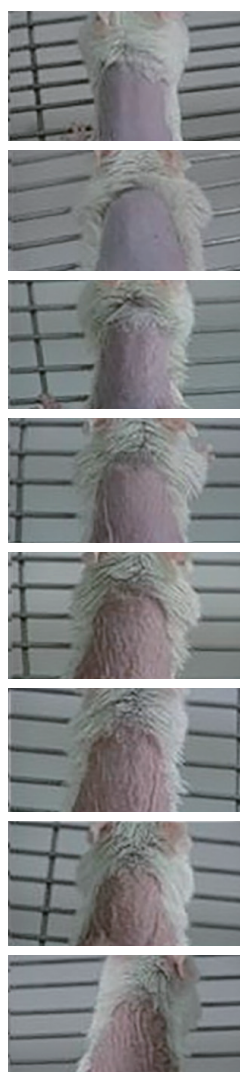

C3
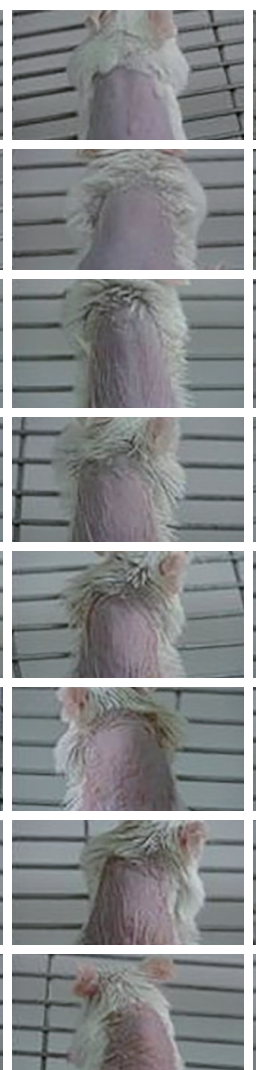

D
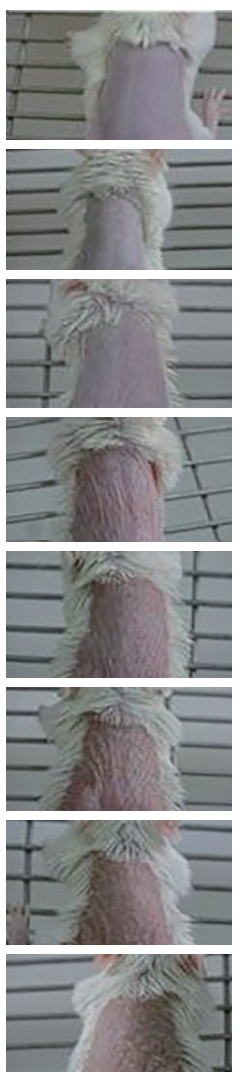

Figure 2 Real-time images of animals in each group after $0-7$ days.

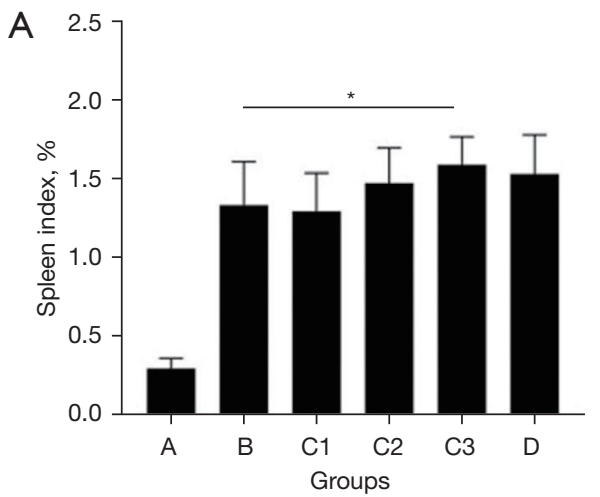

B

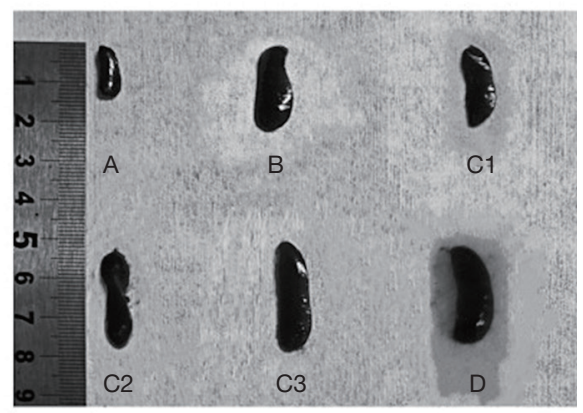

Figure 3 Comparative spleen index (A) and spleen size (B). *, $\mathrm{P}<0.05$ indicates a significant difference compared with group A.

each group was significantly reduced, and the degree of dermal hyperplasia and inflammatory cell infiltration of erythrocytic extravasation was significantly lower than in model group $\mathrm{B}$, and the $\mathrm{C} 3$ effect was the most obvious in the high-concentration hUC-MSCs group (Figure 4).

\section{Skin measurement results}

The epidermal thickness of each group was measured: B $(122 \pm 17.0 \mu \mathrm{m})>\mathrm{C} 1(103 \pm 16.0 \mu \mathrm{m})>\mathrm{C} 2(94 \pm 17.0 \mu \mathrm{m})>\mathrm{D}$ $(78 \pm 8.7 \mu \mathrm{m})>\mathrm{C} 3(69 \pm 12.4 \mu \mathrm{m})$ (Figure 5$)$. In addition to $\mathrm{C} 1$ group $(0.01<\mathrm{P}<0.05)$, there were statistically significant 

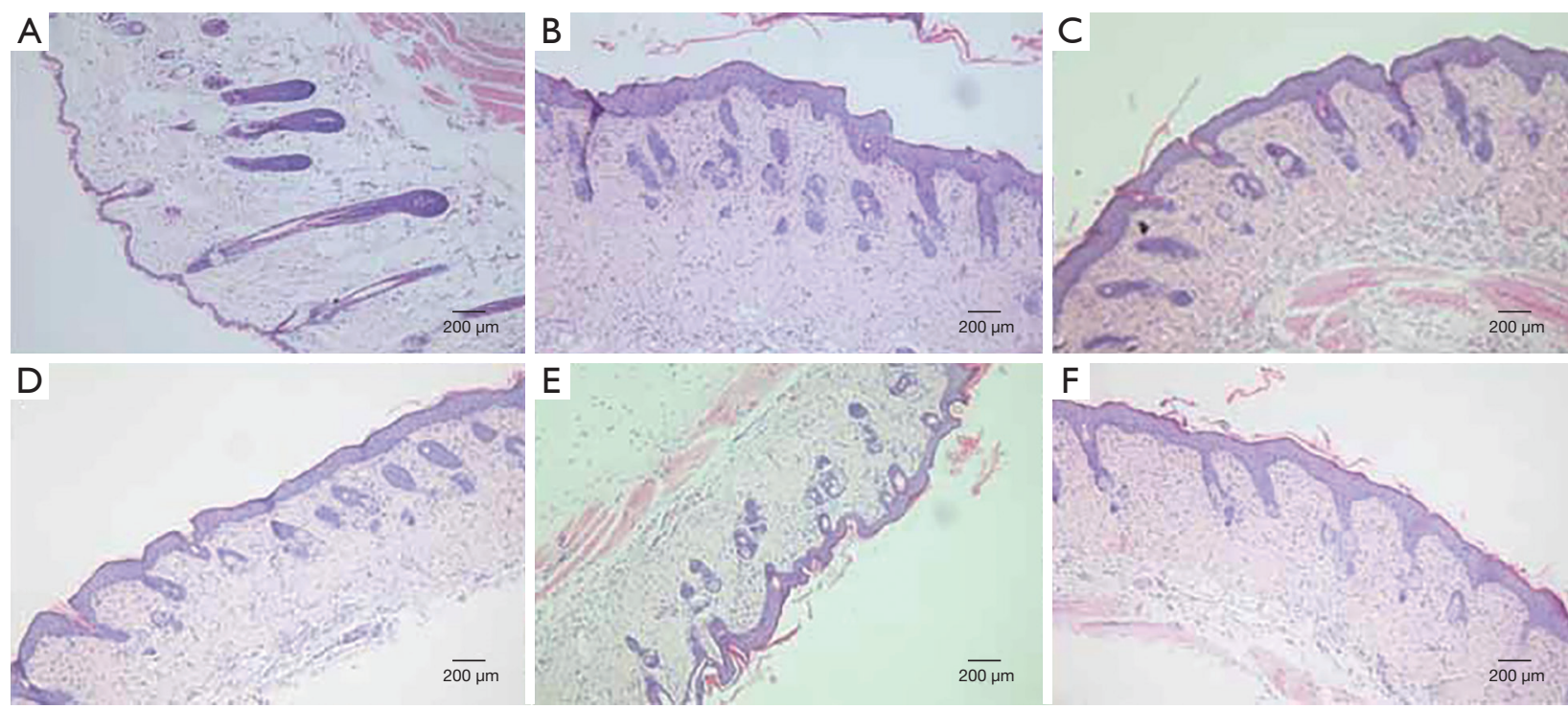

Figure 4 Pathological changes of skin tissue of mice in each group ( $\times 200$, HE). (A) Control group. (B) Model group. (C-E) Treatment C1, C2 and C3 group. (F) Fresh D group.

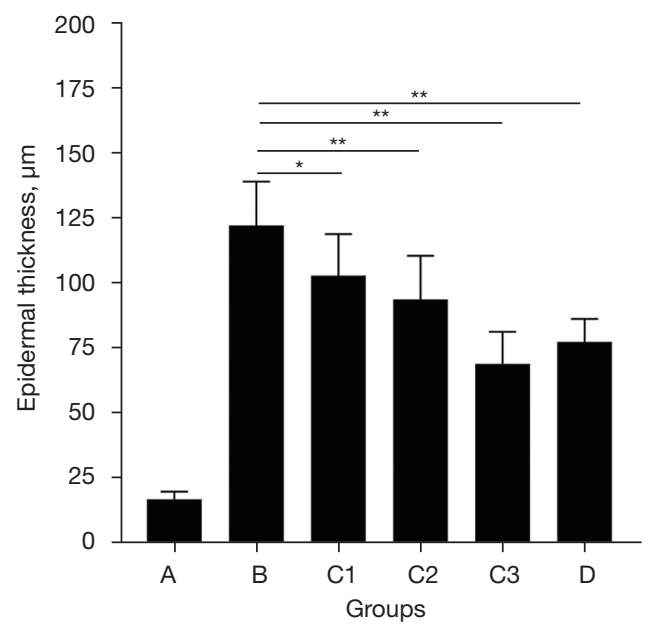

Figure 5 Comparison of epidermal thickness in each group. *, $\mathrm{P}<0.05$ indicates a significant difference compared with group $\mathrm{B}$; **, $\mathrm{P}<0.01$ indicates a significant difference compared with group $\mathrm{B}$.

differences between each treatment group and model group $\mathrm{B}(\mathrm{P}<0.01)$, and there were statistically significant differences in the other groups $(\mathrm{P}<0.01)$.

\section{ELISA test results}

The concentrations of Th1- and Th17-related immune molecules $T N F-\alpha, I F N-\gamma, I L-17 A$ and $I L-23$ in the serum and skin of mice in each group were detected by ELISA
(Tables 2,3; Figures 6,7). We found that the expression concentrations of all cytokines in model group B were higher than those in the other groups. Among them, the expressions of IFN- $\gamma$ and IL-17a in the serum and skin of treatment group $\mathrm{C} 1$ were significantly different from that of model group B, but the expressions of $T N F-\alpha$ and $I L-23$ were not significantly different from that of model group B. Excepting treatment group C1, the concentrations of the four factors in the serum and skin of the other groups were significantly different from those of model group B. Among them, the concentrations of the four cytokines in the serum and skin of the mice administered stem cell preparations with different concentrations were also different, and there was a certain negative correlation. In other words, the higher the dose concentration of the stem cell preparation, the lower the concentration of the four cytokines in serum and skin. These results suggested that the concentration of stem cells had an effect on the cytokine content in the serum and skin of the psoriatic mice.

\section{Immunobistochemical results}

The expression of $I L-36 R N$ protein was detected by immunohistochemistry, and the results showed that its expression level in the hUC-MSCs groups with different concentrations was lower than that in the control group A. However, the expression level of $I L-36 R N$ protein in the 
Table 2 Concentrations of cytokines in the serum of mice as determined by ELISA



Serum concentrations of IFN- $\gamma$, TNF- $\alpha$, IL-17A and IL-23 were measured by ELISA on the 7th day after the death of each group of mice, and the data are the mean \pm labeling difference of 3 independent experiments $(\bar{x} \pm S, n=10)$. ${ }^{*}, P<0.05$ indicates a significant difference compared with group $\mathrm{B} ;{ }^{* *}, \mathrm{P}<0.01$ indicates a very significant difference compared with model group $\mathrm{B}$. ELISA, enzyme-linked immunosorbent assay; IFN, interferon; TNF, tumor-necrosis factor; IL, interleukin.

Table 3 Concentrations of cytokines in skin tissue as determined by ELISA



Concentrations of IFN- $\gamma$, TNF- $\alpha$, IL-17A and IL-23 in the skin of each group were measured by ELISA on the 7th day after the death of each group of mice, and the data are the mean \pm labeling difference of 3 independent experiments $(\bar{x} \pm s, n=10)$. ${ }^{*}, P<0.01$ indicates a very significant difference compared with model group B. ELISA, enzyme-linked immunosorbent assay; IFN, interferon; TNF, tumor-necrosis factor; IL, interleukin.

model group B was significantly lower than that in the other groups. Moreover, in the hUC-MSCs groups with different concentrations, the expression of IL-36RN protein showed an upward trend with increasing hUC-MSC concentration, and the two were positively correlated, which suggested that the administration of hUC-MSCs was related to the expression level of $I L-36 R N$.

\section{Discussion}

Psoriasis is a chronic inflammatory skin disease with a worldwide incidence of $2-3 \%$ (18). The immunological characteristics of psoriasis are immune cell infiltration, hyperkeratosis and parakeratosis, and dilatation of blood vessels in the dermal papilla (19). Psoriasis is mainly classified as erythematous plaque type, spotty type, reverse type, pustular type or erythroderma type (20). The purpose of this study was to evaluate the pharmacodynamics and immune mechanism of hUC-MSCs at different concentrations in delaying psoriatic lesions in an in vivo experimental study in $\mathrm{BALB} / \mathrm{c}$ mice. In mice with psoriatic lesions induced by imiquimod, the lesion severity peaked on days 5-8 and gradually subsided spontaneously due to differences in immune genes between mice and humans. Therefore, in order to ensure that the psoriatic characteristics of the mouse model were maintained for a longer time, in order to observe the efficacy of stem cell therapy, we established an improved psoriasis mouse model according to the method of Xiu et al. (21). After imiquimod cream was applied to the skin, $I L-12$ was added to stimulate the immune system of mice to prolong the duration of skin lesions in the model, making the characteristics of psoriasis more typical, which improves the evaluation of the therapeutic effect of drugs. In addition, given that the 



Figure 6 Concentrations of cytokines IFN- $\gamma$, TNF- $\alpha$, IL-17A and IL-23 in the serum of mice in each group. IFN, interferon; TNF, tumornecrosis factor; IL, interleukin; hUC-MSC, human umbilical cord mesenchymal stem cell.

psoriatic mouse model has a tendency to self-healing, this study was designed to administer the drug before modeling to reduce the effect of stem cells due to the immune factors of the mouse model itself.

The experimental results showed that treatment with hUC-MSCs at different concentrations or with fresh hUCMSCs before modeling led to a slow regression of the psoriatic lesions and a slow decrease in PASI score in model group B and low-dose group C1, while the PASI scores in the medium and high-dose groups $\mathrm{C} 1$ and $\mathrm{C} 2$ became stable and were maintained at a low level. On the 7th day after treatment, the dose of the high-, medium- and lowdose groups was inversely proportional to the curative effect. Moreover, the epidermal thickness was inversely proportional to stem cell concentration. With increasing hUC-MSCs solution concentration, the number of keratinocytes in the experimental groups was significantly reduced, and both the degree of erythrocytic extravasation dermal hyperplasia and inflammatory cell infiltration were reduced, suggesting that hUC-MSCs had therapeutic and interventional effects on the psoriatic lesions in mice, and showed a good dose-dependent relationship.

The spleen size and spleen index of the experimental groups were significantly higher than that of control group $\mathrm{A}$, and the comparison between experimental groups showed that the spleen index increased with increasing of stem cell concentration, suggesting that the spleen may be involved in the immune regulation process of inflammation in mice.

The immune system is involved in the whole process of the occurrence and development of psoriasis. Abnormal activation and infiltration of $\mathrm{T}$ lymphocytes in the epidermis or dermis are important pathophysiological features $(22,23)$. T lymphocytes receive dendritic cells and other antigen-presenting cells to produce $I L-23$, $T N F-\alpha$ induces differentiation and proliferation of CD4+ T lymphocytes (Th17 cells), and mature Th17 cells can secrete various cytokines such as $I L-17, I L-21, I L-22$, etc., which keratinocyte overproliferation or inflammation of synovial cells. Therefore, Th17 cells and the $I L-23 / I L-17$ 

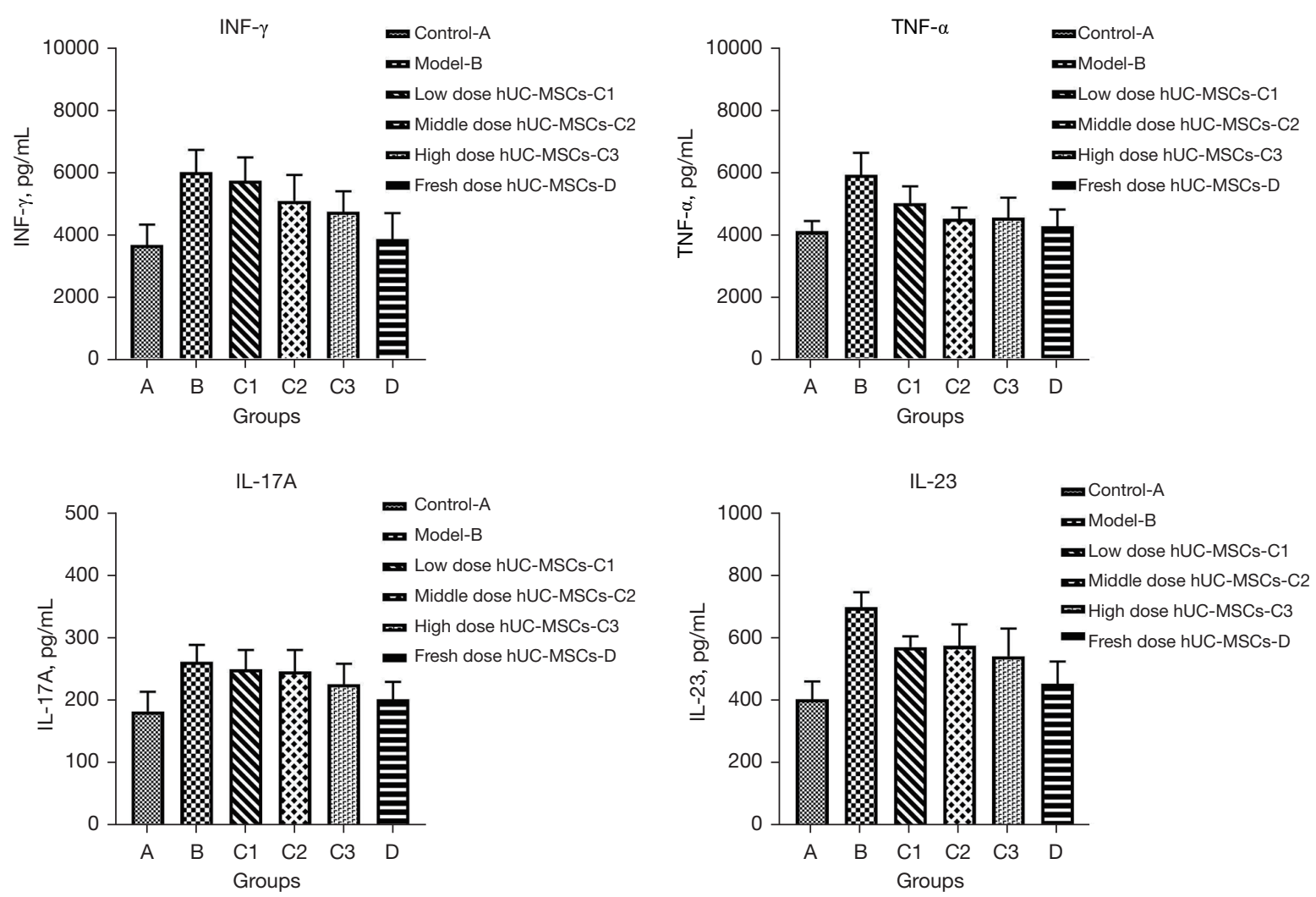

Figure 7 Concentrations of cytokines IFN- $\gamma$, TNF- $\alpha$, IL-17A and IL-23 in the dorsal skin tissue of mice in each group. IFN, interferon; TNF, tumor-necrosis factor; IL, interleukin; hUC-MSC, human umbilical cord mesenchymal stem cell.

axis may be a key link in the pathogenesis of psoriasis and become a new therapeutic target (24). $I L-17$ and $I L-12$ are important cytokines in the $I L-23 / I L-17$ axis and $T h 1 / T h 2$ balance, which are two pathogenic pathways of psoriasis, and there are many biological agents targeting these two cytokines for the treatment of psoriasis (25-27). Therefore, $I L-23$ and $I L-17$ were selected as therapeutic targets in this study.

Therefore, the results of this study suggest that hUC-MSCs have a therapeutic effect on imiquimod-induced psoriasis in mice by inhibiting the concentration of $I L-23$ and $I L-17$ factors. And the higher the concentration of hUC-MSCs, the better the treatment effect.

\section{Acknowledgments}

Funding: This work was supported by Hainan Province Clinical Medical Center and the funding project "Effects of indigo naturalis and Arnebia on differentiation and barrier function of epidermal stem cells in psoriasis response research (Hainan Natural Science Foundation, 20158342)".

\section{Footnote}

Reporting Checklist: The authors have completed the ARRIVE reporting checklist. Available at https://atm. amegroups.com/article/view/10.21037/atm-22-4/rc

Data Sharing Statement: Available at https://atm.amegroups. com/article/view/10.21037/atm-22-4/dss

Conflicts of Interest: All authors have completed the ICMJE uniform disclosure form (available at https://atm. amegroups.com/article/view/10.21037/atm-22-4/coif). The authors report that research was supported by Hainan Province Clinical Medical Center and the funding project "Effects of indigo naturalis and Arnebia on differentiation and barrier function of epidermal stem cells in psoriasis response research (Hainan Natural Science Foundation, 20158342)”. HW, CJ, CC, DS, FX, HZ, HW are from 
Asia Stem Cell Regenerative Pharmaceutical Co., Ltd. The authors have no other conflicts of interest to declare.

Ethical Statement: The authors are accountable for all aspects of the work in ensuring that questions related to the accuracy or integrity of any part of the work are appropriately investigated and resolved. Experiments were performed under a project license (No. 2016LL003) granted by institutional board of The Fifth People's Hospital of Hainan Province, in compliance with The Fifth People's Hospital of Hainan Province guidelines for the care and use of animals.

Open Access Statement: This is an Open Access article distributed in accordance with the Creative Commons Attribution-NonCommercial-NoDerivs 4.0 International License (CC BY-NC-ND 4.0), which permits the noncommercial replication and distribution of the article with the strict proviso that no changes or edits are made and the original work is properly cited (including links to both the formal publication through the relevant DOI and the license). See: https://creativecommons.org/licenses/by-nc-nd/4.0/.

\section{References}

1. Boehncke WH, Schön MP. Psoriasis. Lancet 2015;386:983-94.

2. Amigó M, Schalkwijk J, Olthuis D, et al. Identification of avarol derivatives as potential antipsoriatic drugs using an in vitro model for keratinocyte growth and differentiation. Life Sci 2006;79:2395-404.

3. Saelee C, Thongrakard V, Tencomnao T. Effects of Thai medicinal herb extracts with anti-psoriatic activity on the expression on NF- $\mathrm{KB}$ signaling biomarkers in $\mathrm{HaCaT}$ keratinocytes. Molecules 2011;16:3908-32.

4. Bocheńska K, Smolińska E, Moskot M, et al. Models in the Research Process of Psoriasis. Int J Mol Sci 2017;18:2514.

5. Schleicher SM. Psoriasis: Pathogenesis, Assessment, and Therapeutic Update. Clin Podiatr Med Surg 2016;33:355-66.

6. Reich K, Mrowietz U, Radtke MA, et al. Drug safety of systemic treatments for psoriasis: results from The German Psoriasis Registry PsoBest. Arch Dermatol Res 2015;307:875-83.

7. Kim WB, Jerome D, Yeung J. Diagnosis and management of psoriasis. Can Fam Physician 2017;63:278-85.

8. Coates LC, Merola JF, Grieb SM, et al. Methotrexate in Psoriasis and Psoriatic Arthritis. J Rheumatol Suppl 2020;96:31-5.

9. Mozzanica N, Pigatto PD, Finzi AF. Cyclosporin in psoriasis: pathophysiology and experimental data. Dermatology 1993;187 Suppl 1:3-7.

10. Warren EW, Khanderia U. Use of retinoids in the treatment of psoriasis. Clin Pharm 1989;8:344-51.

11. Greaves MW, Dawber R. Azathioprine in psoriasis. Br Med J 1970;2:237-8.

12. Schleicher SM. Efficacy and emergent sequelae in the use of biologics for psoriasis. Emerg Med 2010;42:6-11.

13. Castro-Manrreza ME, Bonifaz L, Castro-Escamilla O, et al. Mesenchymal Stromal Cells from the Epidermis and Dermis of Psoriasis Patients: Morphology, Immunophenotype, Differentiation Patterns, and Regulation of T Cell Proliferation. Stem Cells Int 2019;2019:4541797.

14. Hou R, Li J, Niu X, et al. Stem cells in psoriasis. J Dermatol Sci 2017;86:181-6.

15. Lin X, Meng X, Song Z. Homocysteine and psoriasis. Biosci Rep 2019;39:BSR20190867.

16. Zhou F, Zhu Z, Gao J, et al. NFKB1 mediates Th1/Th17 activation in the pathogenesis of psoriasis. Cell Immunol 2018;331:16-21.

17. Lowes MA, Suárez-Fariñas M, Krueger JG. Immunology of psoriasis. Annu Rev Immunol 2014;32:227-55.

18. González-Parra S, Daudén E. Psoriasis and Depression: The Role of Inflammation. Actas Dermosifiliogr (Engl Ed) 2019;110:12-9.

19. Navarini AA, Trüeb RM. Psoriasis. Ther Umsch 2010;67:153-65.

20. Benezeder T, Wolf P. Resolution of plaque-type psoriasis: what is left behind (and reinitiates the disease). Semin Immunopathol 2019;41:633-44.

21. Xiu YJ, Xiang CY, Shao ZJ. Establishment of modified psoriasis mouse model. China Pharmacy 2019;30:5

22. Hawkes JE, Chan TC, Krueger JG. Psoriasis pathogenesis and the development of novel targeted immune therapies. J Allergy Clin Immunol 2017;140:645-53.

23. Nussbaum L, Chen YL, Ogg GS. Role of regulatory $\mathrm{T}$ cells in psoriasis pathogenesis and treatment. $\mathrm{Br} \mathrm{J}$ Dermatol 2021;184:14-24.

24. Hawkes JE, Yan BY, Chan TC, et al. Discovery of the IL-23/IL-17 Signaling Pathway and the Treatment of Psoriasis. J Immunol 2018;201:1605-13.

25. Furue K, Ito T, Tsuji G, et al. Psoriasis and the TNF/IL23/IL17 axis. G Ital Dermatol Venereol 2019;154:418-24. 
26. van der Fits L, Mourits S, Voerman JS, et al. Imiquimodinduced psoriasis-like skin inflammation in mice is mediated via the IL-23/IL-17 axis. J Immunol 2009; 182:5836-45.

Cite this article as: Lin $\mathrm{Y}$, Wang $\mathrm{H}$, Jiang C, Chen C, Shen D, Xie F, Zhang H, Yang J, Wang H. Effects of different concentrations of human umbilical cord mesenchymal stem cells to ameliorate psoriasis-like skin lesions in BALB/c mice. Ann Transl Med 2022;10(2):86. doi: 10.21037/atm-22-4
27. Kamata M, Tada Y. Safety of biologics in psoriasis. J Dermatol 2018;45:279-86.

(English Language Editor: K. Brown) 